Sādhanā Vol. 38, Part 6, December 2013, pp. 1451-1468. (C) Indian Academy of Sciences

\title{
Geostatistical interpolation for modelling SPT data in northern Izmir
}

\author{
SELIM ALTUN $^{1}$, A BURAK GÖKTEPE ${ }^{2}$ and ALPER SEZER ${ }^{1, *}$ \\ ${ }^{1}$ Civil Engineering Department, Ege University, 35100, Izmir, Turkey \\ ${ }^{2}$ Rruga Bilal Golemi, Tirana, Albania \\ e-mail: alper.sezer@ege.edu.tr; selim.altun@ege.edu.tr; abgoktepe@gmail.com
}

MS received 17 March 2012; revised 25 January 2013; accepted 16 April 2013

\begin{abstract}
In this study, it was aimed to map the corrected Standard Penetration Test (SPT) values in Karşıyaka city center by kriging approach. Six maps were prepared by this geostatistical approach at depths of 3, 6, 9, 13.5, 18 and $25.5 \mathrm{~m}$. Borehole test results obtained from 388 boreholes in central Karş1yaka were used to model the spatial variation of $\left(\mathrm{N}_{1}\right)_{60 \mathrm{cs}}$ values in an area of $5.5 \mathrm{~km}^{2}$. Corrections were made for depth, hammer energy, rod length, sampler, borehole diameter and fines content, to the data in hand. At various depths, prepared variograms and the kriging method were used together to model the variation of corrected SPT data in the region, which enabled the estimation of missing data in the region. The results revealed that the estimation ability of the models were acceptable, which were validated by a number of parameters as well as the comparisons of the actual and estimated data. Outcomes of this study can be used in microzonation studies, site response analyses, calculation of bearing capacity of subsoils in the region and producing a number of parameters which are empirically related to corrected SPT number as well.
\end{abstract}

Keywords. Kriging; SPT; site investigations; land-use planning; modelling; Northern Izmir.

\section{Introduction}

Evaluation of properties of soils beneath and adjacent to the structures at a specific region is of main importance in terms of geotechnical considerations since behaviour of structures is strongly influenced by the seismic response of soils. Obviously, properties of the soils surrounding the structure are also effective on the bearing capacity. From the viewpoint of the engineers, a correct assessment of these properties necessitates a plausible bilateral evaluation of geotechnical

*For correspondence 
and geological data. In other words, after the evaluation of the geological units in a region, the geotechnical properties of the soils to a desired depth are determined by field and laboratory studies. A number of field tests including Standard Penetration Test (SPT), Cone Penetration Test (CPT), Vane Shear Test, Dilatometer Test, etc. can be employed to find out the strength and other engineering properties of the soils.

It is acknowledged that all tests have a number of limitations, advantages as well as drawbacks and application of different tests on various types of soils requires an extensive study in decision making processes (Bowles 1997; Budhu 2007). Standard penetration test is barely the most common in-situ test in geotechnical engineering, which is used in evaluating the strength variation of soil strata underlying structures (Sivrikaya \& Togrol 2006). The test is applicable to a widely ranged soil conditions. Although the use of this test is prevalent in subsurface investigations, it has some major drawbacks. The results are affected from many factors and discrepancies in test results are noted in the literature due to use of equipment from different manufacturers, drive hammer configurations, hammering system, use of liner inside the split barrel sampler, overburden pressure, length of drill rod and other problems in application. The test exhibits different driving resistances in silts and clays of varying moisture contents. In some cases, the test results are ambiguous due to the high uncertainty in the soil medium as well as the problem of representing the strength parameters of a soil layer with a single SPT number experienced at a predetermined depth. In some cases, this is the reason for the misinterpretation of the soil properties and overlying superstructure.

Because of the reasons mentioned above, uncertainties or limitations of the test may cause misinterpretation of the soil strength as well as their engineering properties and responses. Therefore, validation or prediction of soil properties using a number of mathematical and statistical parameters has emerged as a supplementary approach to soil investigations in a region. However, these predictions involve pitfalls due to the uncertainty arising from spatial variability, measurement and model bias, the density of measurements, as well as their high variability in a specific zone (Baecher 1984). Indeed, the soil properties possess extremely high uncertainty in three-dimensions and according to Whitman (2000), the uncertainty sources in geotechnical engineering can be classified into 'data scatter' and 'systematic error'. While the former includes uncertainty related with the spatial variability and random testing errors, the latter includes measurement errors and statistical errors due to lacking of data. It should be mentioned that, uncertainty related to 'data scatter' stems from the natural randomness of the system under consideration and decreasing this uncertainty needs a laborious work, which is not cost-effective. Furthermore, decreasing the distances between site investigation locations will not always cause an increase in the quality of the data. On the other hand, 'systematic error' is due to the capabilities and experience of the engineers, which may cause unacceptable shortcomings and misuse of equipments in field data acquisition and evaluation. This study focuses on the representation of uncertainty in data scatter, which may be a useful study for the spatial variability of soils underlying Karşıyaka municipality.

Geostatistical methods were originally used for ore reserve calculations by the pioneering study of Krige (1951) and later the theory was rewritten in a very concise way by Matheron's fabulous contributions (Duval et al 1955). A new scientific discipline, namely, geostatistics, emerged by unifying Krige's concepts and Matheron's theory of regionalized variables (Matheron 1970). This method has been increasingly used in many disciplines due to the developments in computer science and Geographic Information System (GIS). The superiority of geostatistics in comparison with ordinary statistics is the inverse proportion between the strength of correlation among pre-defined parameters at two points under consideration and the distance between these points. Increasing the density of sampling points both in plan and depth is not cost 
effective. Furthermore, because of space requirements, it is hard to employ site investigations in every desired point. For this reason, leveraging geostatistics benefits the spatial variability of any parameter by a correlative approach. Variogram models built from experimental variograms and spatial correlations enable us to describe the variation of the underlying geostatistical data in a continuous manner. The variogram model is then charged to make predictions at unknown and desired points by Kriging method.

As mentioned before, this method has been widely used in many disciplines. In geotechnical engineering, various attempts have been concentrated on evaluation of field data. Jaksa (1995) utilized random field theory and geostatistics to model and predict the spatial variability of Keswick and Hindmarsh Clays in Australia. A number of studies have been carried out to model SPT data using geostatistics (Mansor 2003; Mendes \& Lorandi 2003; Sitharam \& Samui 2007; Basarir et al 2010; Samui \& Sitharam 2010). Using either corrected or uncorrected SPT data, the underlying soils were characterized in a continuous manner and maps for prediction purposes were prepared. In all of these studies, it was underlined that, the predicted values can then be used to estimate subsoil geotechnical parameters for prediction of bearing capacity, modulus of elasticity as well as shear wave velocity. The generalization and modelling ability of the method was found satisfactory. Literature also contains studies concerning application of the method on CPT test results along with those of SPT, aiming to prepare liquefaction potential maps (Lenz \& Baise 2007). Nonetheless, the studies were not solely limited to SPT and CPT evaluations, the scope of the subsequent studies embraced liquefaction potential evaluation (Parsons \& Frost 2002; Dawson \& Baise 2005; Baise et al 2006; Lenz \& Baise 2007; Baker \& Faber 2008). These studies focused on mapping a specific region in terms of Liquefaction Potential Index (LPI) parameter coupled with groundwater surface level, cyclic stress ratio (CSR) value as well as the geological interpretations. Needless to say, the maps were prepared by kriging method. Additionally, Carvalho \& Cavalheiro (2005) employed geostatistical methods and Fourier analyses to model the cross-hole seismic tomography test results in a site in Porto and mapped shear modulus and Poisson's ratio variation. Al-Suba'i \& Barat (2006) presented a detailed map showing the types of soils and rocks in Sana city, which was created by kriging technique. Information was also given about a number of geotechnical characteristics of the underlying soils of Sana city including grain size distribution, plasticity, strength parameters and water content, for interpolation and estimation purposes.

In the light of these previous works, in this study, it was aimed to map the SPT results in central Karşıyaka city (İzmir) by use of geostatistics. The results were mapped in UTM projection and the variation of corrected SPT values were contoured at 3, 6, 9, 13.5, 15 and $25.5 \mathrm{~m}$ depths. Besides, the results were validated in terms of a number of statistical parameters and the comparison of the model outcomes and the real SPT values in two bore holes, which can be useful for a predetermination of SPT value in the field in preliminary designs, microzonation and liquefaction analyses.

\section{Investigation area}

Municipality of Karşıyaka is located in the north of İzmir city $\left(38.45 \mathrm{~N}\right.$ and $\left.27.12^{\circ} \mathrm{E}\right)$ and on the west coast of Turkey (figure 1a). Karşıyaka County is adjacent to İzmir metropolis and its population is over 300.000. River Gediz meets the Aegean Sea by forming a delta to the left of the investigation area, which is the reason for the alluvial stratum on the topmost layer. Depth to bedrock is up to $150-300 \mathrm{~m}$ in the area and the field as well as laboratory investigations revealed 


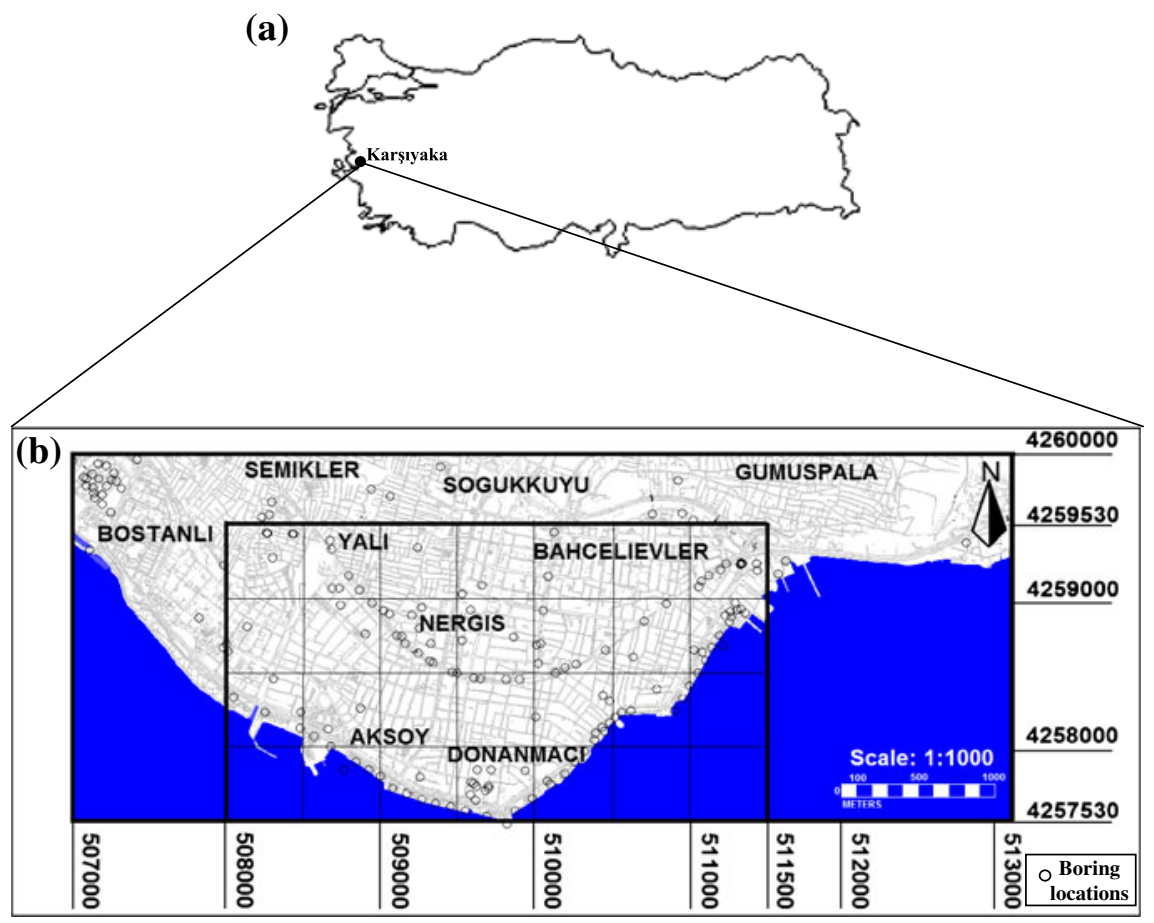

Figure 1. (a) Location of Karşıyaka municipality in Turkey and (b) investigation area and the bore hole locations.

that the soils in the area have very poor engineering properties. Boring results show that the soils in the area are dominantly clays of high plasticity, silts and mica based loose sands down to $35 \mathrm{~m}$ of depth. The city center, which is in the investigation area, is highly populated with multistorey buildings. It should be noted that, deep soil investigations were not conducted in the city center in the past. Although it is compulsory to make detailed subsoil investigations on constructional areas today, deficiencies in law-making in the past caused insufficient number and distribution of subsurface investigations in highly populated city center. Furthermore, the earthquake risk is increasing in the region since the last catastrophic earthquake happened approximately 230 years ago (Emre et al 2005).

Therefore, the main goal in this study was to model the variation of corrected SPT number with depth by geostatistical approach and to present it for use in subsoil investigations and research projects. The city center and the neighbouring district centers are shown in figure $1 \mathrm{~b}$. The figure also includes the boring locations as well as the limits of the area under consideration. The investigation area is approximately $5.5 \mathrm{~km}^{2}$ and the city is situated $5 \mathrm{~m}$ above mean sea level.

In the region, two units constitute the lithostratigraphic sequence. The Mount Yunt volcanics and Quaternary sediments. The northern part of the Izmir Gulf was formed by the Mount Yunt volcanic rocks: Upper Miocene rocks overlies the Neogene aged sedimentary rocks which were formed by volcanic activities. While the volcanic rocks contain lithic tuffs, agglomerates and andesites constitute the Quaternary unit formed by slope wash and alluvium (Koca \& Kincal 2004; Çiftçi \& Bozkurt 2009). 


\section{Geotechnical database and mapping}

Standard penetration tests, which are the most common tests used in subsurface investigations in Turkey and other countries, are conducted by driving a standard split spoon sampler into soil at a standardized energy. Here, the standardized energy is obtained by a free-fall hammer of $63.5 \mathrm{~kg}$ weight falling from a height of $76 \mathrm{~cm}$. By counting the number of falls, the sampler is initially driven $15 \mathrm{~cm}$ to the soil for passing through the disturbed part. The sum of blow counts belonging to the next two $15 \mathrm{~cm}$ driving is recorded as the SPT number. If the number of blows exceeds 50 for any $15 \mathrm{~cm}$ driving or 10 successive blows causes no penetration, a ' $\mathrm{R}$ ' indicating 'refusal' is entered into boring log. SPT-N values should be multiplied by use of overburden $\left(C_{N}\right)$, hammer energy $\left(C_{E}\right)$, rod length $\left(C_{R}\right)$, sampler $\left(C_{S}\right)$, borehole diameter $\left(C_{B}\right)$ and fines content $\left(C_{\text {fines }}\right)$ correction factors (Bowles 1997; Önalp \& Sert 2010). Normalizing the corrected SPT-N values up to $60 \%$ of standard energy, the following equation can be written

$$
\left(N_{1}\right)_{60}=\frac{(S P T-N) \times C_{E} \times C_{R} \times C_{B} \times C_{S} \times C_{N}}{0.60},
$$

where, $\left(\mathrm{N}_{1}\right)_{60}$ is the corrected number of blow counts (Önalp \& Sert 2010). Following formula is proposed for overburden correction

$$
C_{N}=\left[\frac{95.76}{\sigma^{\prime}}\right]^{1 / 2}
$$

In this equation, $\sigma^{\prime}(\mathrm{kPa})$ is the effective overburden pressure (Önalp \& Sert 2010). It should be underlined that the correction is made for $C_{N}$ values smaller than or equal to 1.7. The fines content correction $\left(C_{\text {fines }}\right)$ is proposed by Çetin et al (2004)

$$
\left(N_{1}\right)_{60_{c s}}=\left(N_{1}\right)_{60} \times C_{\text {fines }},
$$

where, $C_{\text {fines }}$ is calculated by

$$
C_{\text {fines }}=[1+0.004 \times F C]+0.05 \times \frac{F C}{\left(N_{1}\right)_{60}} \text { where, }\{5 \%<F C<30 \%\} .
$$
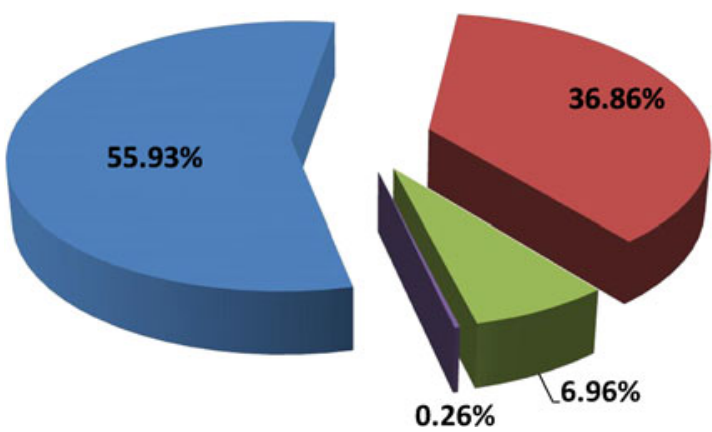

Inside

NW

$\square \mathrm{N}$

NE

Figure 2. Distribution of the field investigation locations inside and outside the investigation area. NW, $\mathrm{N}$ and $\mathrm{NE}$ are the locations of data points relative to the area under investigation. 


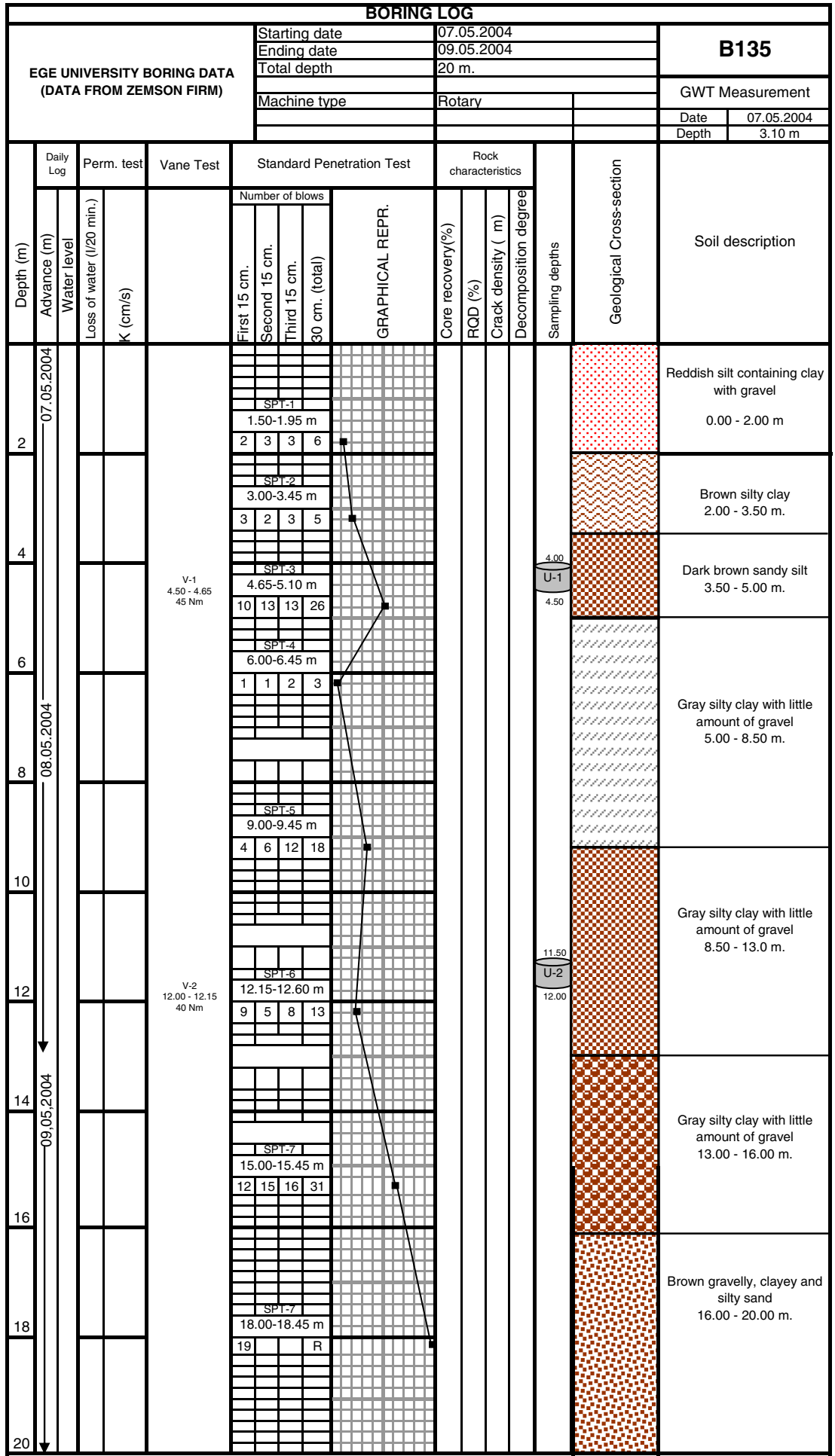

Figure 3. A typical bore hole log from a subsurface investigation. 
In this equation, $\mathrm{FC}$ is the percentage of fines, which is the material passing through No.200 sieve.

Therefore, in this study, the results of SPT tests carried out in the field by four boring companies were prepared in electronic format in separate files. 388 test results which were carried out inside and around the area were reported. The distribution of the subsurface investigation locations in the investigation area is given in figure 2. The data represented in N, NW and NE direction are outside the area under investigation, but were included in database for interpolation purposes. Being an old District, NE of the area has not been adequately investigated, thus, there is little amount of data in hand. Also, the area is encircled by Izmir Gulf from the south direction. After collecting the data and constituting the database, a Matlab 7.0 code was written to unify the test results in a single file. The data was arranged to a depth of $30 \mathrm{~m}$ below the ground surface level. Data sheet contains information including SPT-N values, unit weight of the soil at various levels, depth of ground water table, etc.

Meanwhile, digitized maps of 1:1000 scale were obtained. These maps include information about streets, residential information, number of permitted storeys for each boulevards, streets, elevation contours, residential density, etc. These maps were transferred to MAPINFO software and the information was presented using a GIS package.

It is hard to represent a generalized soil profile for the region, or its neighbouring areas. The significant fact about the region is that the bedrock is deeper than $30 \mathrm{~m}$ in the investigation area. In NW direction outside the investigation area, namely the Bostanli District, geophysical investigations revealed that the bedrock surface level is deeper than $200 \mathrm{~m}$ from the ground surface level. Investigations carried out in the area came up with poor engineering properties of soils and very high ground water table levels. A sample borelog of the investigations in the area is given in figure 3. The boring log includes information about ground water table depth, field and laboratory test results as well as the soil strata encountered. Although the bore hole test results cannot be represented as a descriptive boring log since the outcomes of the tests are highly variable in the

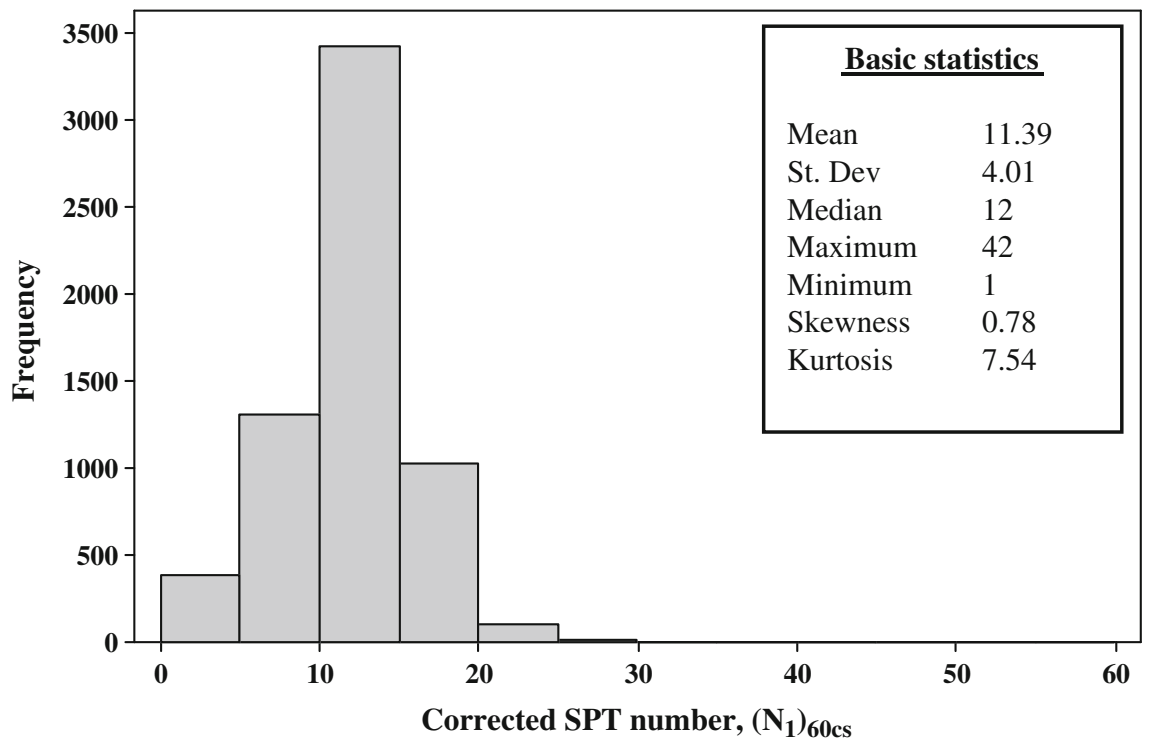

Figure 4. Basic statistical analysis and histogram of the $\left(\mathrm{N}_{1}\right)_{60 \mathrm{cs}}$ values. 
region, it is apparent that, soft clays, loose sands and soils with poor engineering properties (e.g., unfavourable soil class, low strength, unacceptable compressive behaviour) overlie the bedrock. Inside the investigation area, namely Aksoy, Donanmacı and Nergis Districts, detected equivalent shear wave velocities in the upper $30 \mathrm{~m}$ range between $100-300 \mathrm{~m} / \mathrm{s}$, varying from point to point.

A histogram as well as the basic statistical analysis of the $\mathrm{N}_{60 \mathrm{cs}}^{\prime}$ values are given in figure 4, which can form an opinion about the properties of the soils in the region. It is understood that the histogram of the corrected SPT values are left skewed and the values are concentrated from 10 to 15 . Mean value is 11.39 , with a standard deviation of 4.01 . Besides, high kurtosis number is the indicator of the sharp peak, which is also observed from the frequency distribution.

\section{Kriging-An overview}

Kriging is known as a mathematical procedure to estimate the unknown regionalized parameters at locations with a minimum error variance. The method is beneficial in calculating grid node parameters by interpolation on contour maps. Theoretically, estimation capabilities of kriging method are better in comparison with the remaining methods relying on the facts that it is unbiased and based on minimizing the error. Actually, the accuracy of the variogram, related to the covariance function between two points is strictly effective on the quality of the grid formation by kriging method. Experimental variograms are used to present the spatial variation of the regionalized random variable where predefined mathematical models are fitted for use in mapping (Huijbregts 1975; Olea 1991; Rota 2007). In order to describe the variation of variable $z(u)$, at locations $u$, experimental variograms were used. The variograms enable the measurement of the dissimilarity between $z(u)$ and the neighbouring datum. The correlation between two neighbouring points was assumed to be dependent on the lag distance between them. Anisotropy, the dependency to direction, was also effective on the spatial correlation, namely, the semivariogram.

The variogram, $\gamma(h)$ can be described as the magnitude of dependence between attributes at two different locations:

$$
\gamma(h)=0.5 \times E\left\{[Z(u)-Z(u+h)]^{2}\right\},
$$

where $Z(u)$ and $Z(u+h)$ are two variables measured at different locations and $h$ is the vector expressing the lag distance between the two locations. Within a pre-defined length interval and desirably oriented within a tolerated angle, the experimental values are used to plot the variogram by computing the average squared difference between the values separated by a lag $\mathrm{h}$ :

$$
\gamma(h)=0.5 \times[N(h)]^{-1} \sum_{i=1}^{N(h)} E\left\{[Z(u)-Z(u+h)]^{2}\right\},
$$

where $N(h)$ is the number of data pairs separated within a pre-defined lag distance, $Z(u)$ and $Z(u+h)$ are the observed values of the variable, which are separated by the vector $h$ (Sitharam \& Samui 2007).

Basic components of a variogram are shown in figure 5. The identifiers of a variogram can be counted as the nugget, sill and the range parameters. Although the nugget is simply the ordinate value of the intersection of the variogram and the y-axis, it is generally referred as a particular model (Rota 2007). For modelling the remaining section, there are a number of models including 


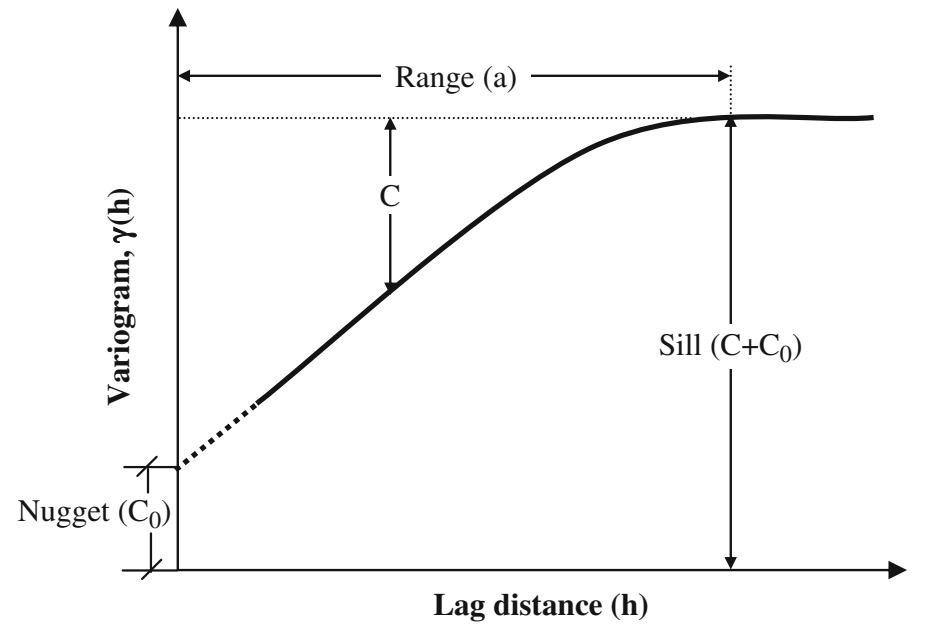

Figure 5. Typical variogram and its components.

exponential, spherical, Gaussian, linear, hole effect, etc. (Sitharam \& Samui 2007; Mendes \& Lorandi 2008). After the experimental variogram is built up, the convergence of fit of mathematical models to data in hand was investigated. In this study, the exponential model was preferred due to its simplicity and in accordance with experimental results. The spatial behaviour the $\left(\mathrm{N}_{1}\right)_{60 \mathrm{cs}}$ parameter could be best represented by this model. The exponential model is formulated as in Eq. (7):

$$
\begin{gathered}
\text { if } h=0 \text { then } \gamma(h)=0 \\
\text { if } h \neq 0 \text { then } \gamma(h)=C_{0}+C \times\left[1-\frac{1}{e^{\frac{h}{a}}}\right] .
\end{gathered}
$$

In this formulation, $C_{0}$ and $a$ are titled as the nugget and range of the model, respectively. $C_{0}+C$ is the sill, which can be defined as the constant value of the variogram, as the lag distance exceeds the range value. Subsequently, the kriging technique should be employed to find out the estimates of the desired parameter at each node of the grid under the considerations and attributes of the experimental variogram. For instance, in order to predict the parameter under consideration at grid node $\left(Z_{u(0)}^{*}\right)$, which is given in figure 6 , experimental values at $n$ locations are utilized. The aim is to calculate $Z$ parameter at point $u(0)$ (Journel 1989):

$$
Z_{u(0)}^{*}=\lambda_{0}+\sum_{i=1}^{n} \lambda_{i} \times Z_{u(i)},
$$

$\lambda_{i}$ parameter should be determined so that the $Z_{u(0)}^{*}$ estimate should be unbiased and has a minimized square error. Expected $E\left[Z_{u(0)}-Z_{u(0)}^{*}\right]$ should be zero

$$
E\left[Z_{u(0)}^{*}\right]=E\left[\lambda_{0}+\sum_{i=1}^{n} \lambda_{i} \times Z_{u(i)}\right] .
$$




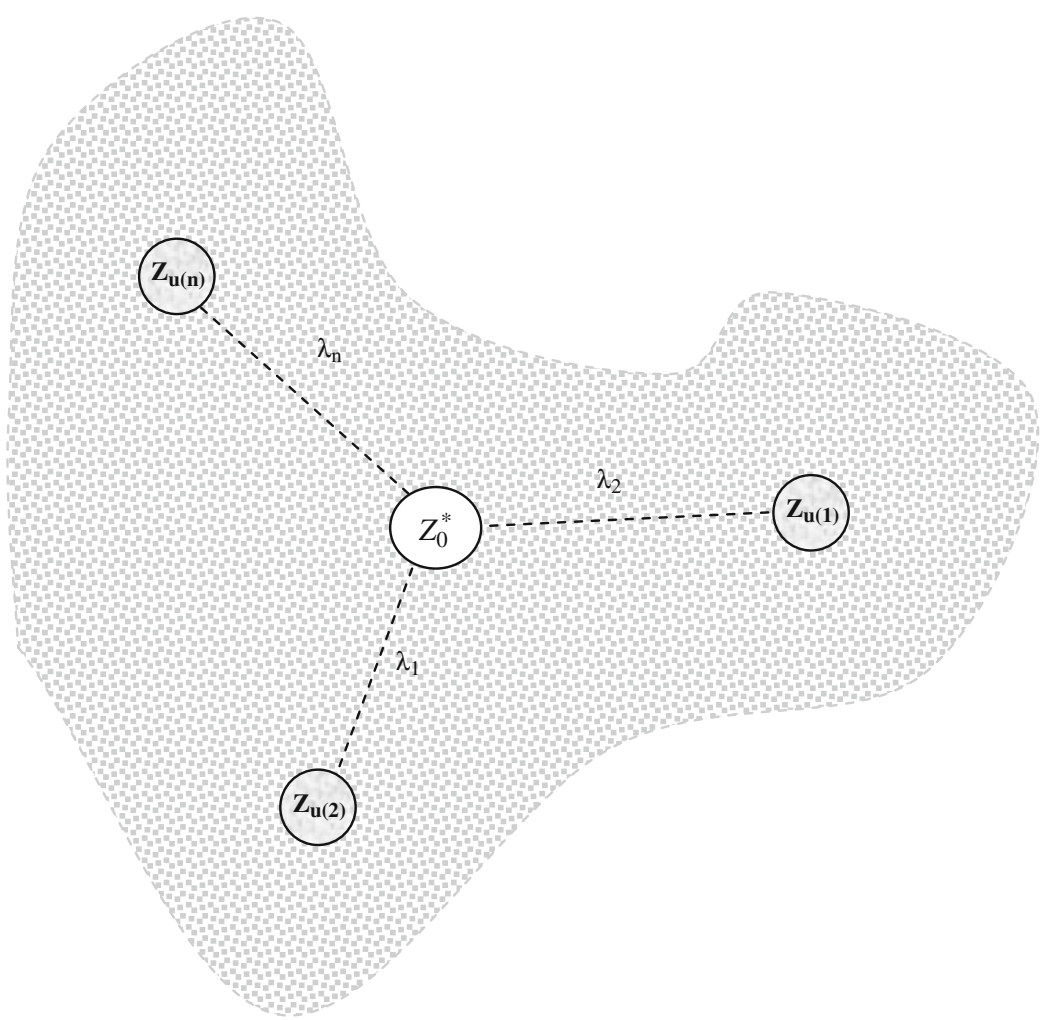

Figure 6. Kriging-search for the parameter at point $Z_{u(0)}^{*}$ by use of the experimental values at neighbouring points.

Similar relationships can be established by the mean value, $m$

$$
m=\lambda_{0}+\sum_{i=1}^{n} \lambda_{i} \times m
$$

For $\lambda_{0}=0$, the estimates are given by

$$
Z_{u(0)}^{*}=\sum_{i=1}^{n} \lambda_{i} \times Z_{u(i)} ; \quad \sum_{i=1}^{n} \lambda_{i}=1 .
$$

The error variance at point 0 is minimized by the following equation to calculate the weights (Journel 1989; Mendes \& Lorandi 2008)

$$
\sum_{k=1}^{n} \lambda_{k} \times C[u(i), u(k)]-\alpha=C[u(i), u(0)] \quad \text { for all } k=1, n \text { and } \sum_{k=1}^{n} \lambda_{k}=1 .
$$

In this equation, $C$ is the variance between pre-determined two points and $\alpha$ is the Lagrange coefficient used in the minimization of the error variance. 


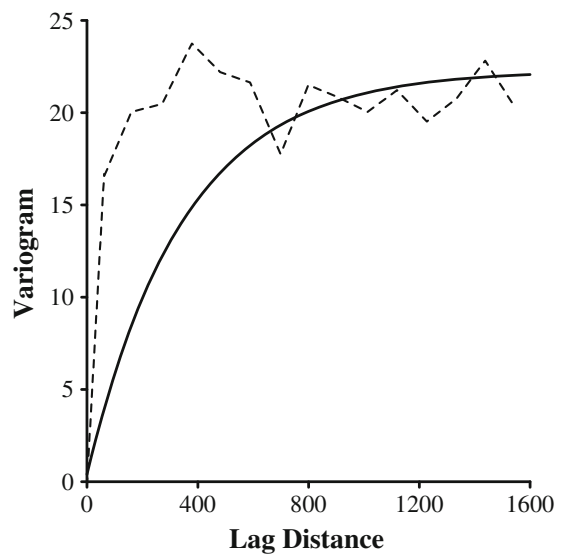

(a)

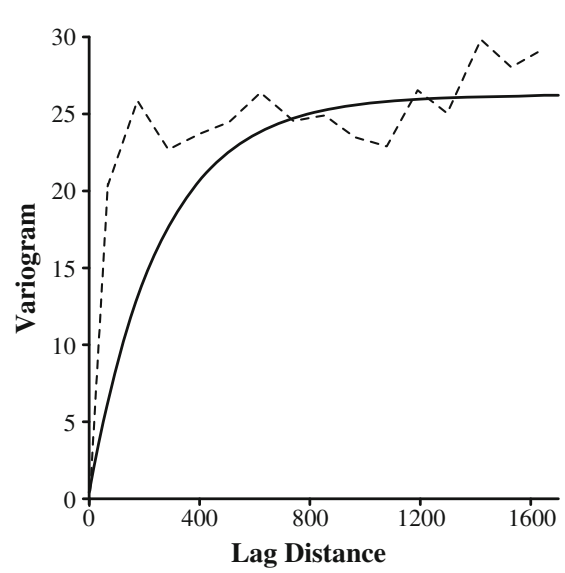

(c)

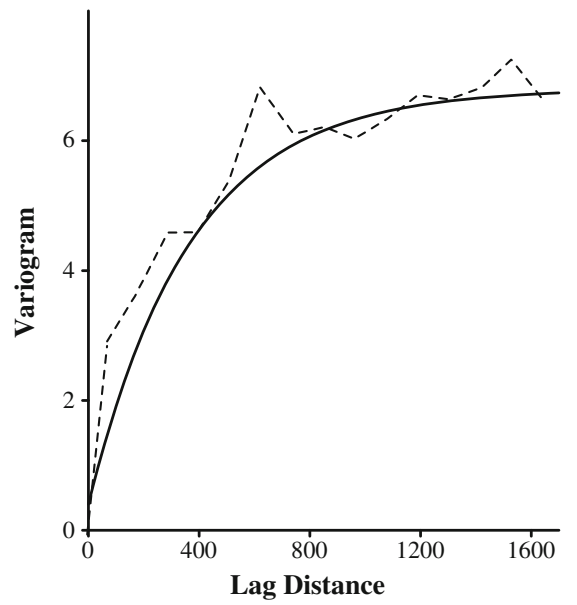

(e)

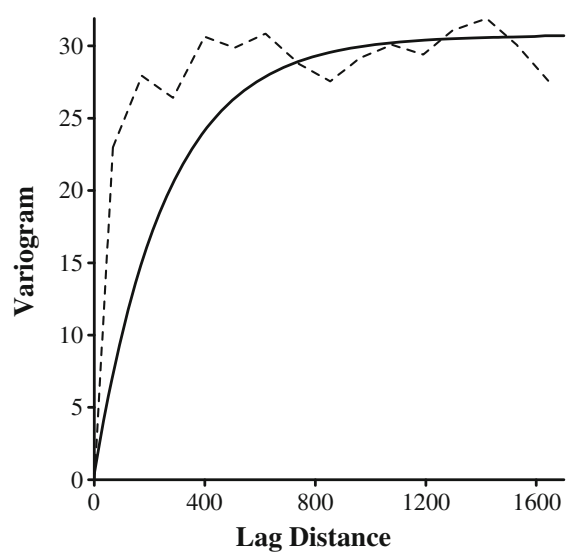

(b)

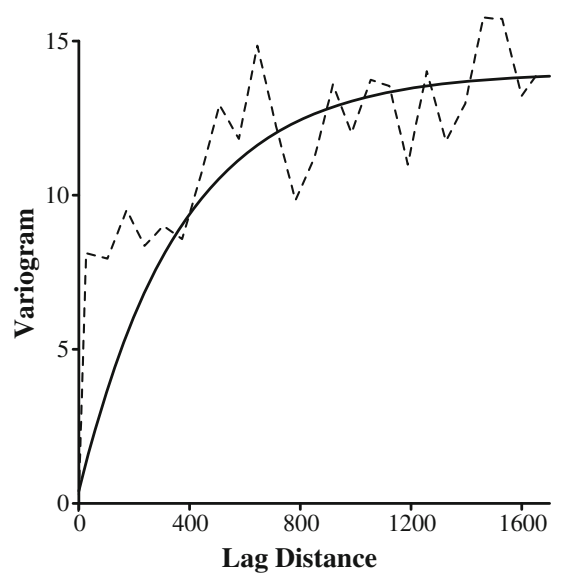

(d)

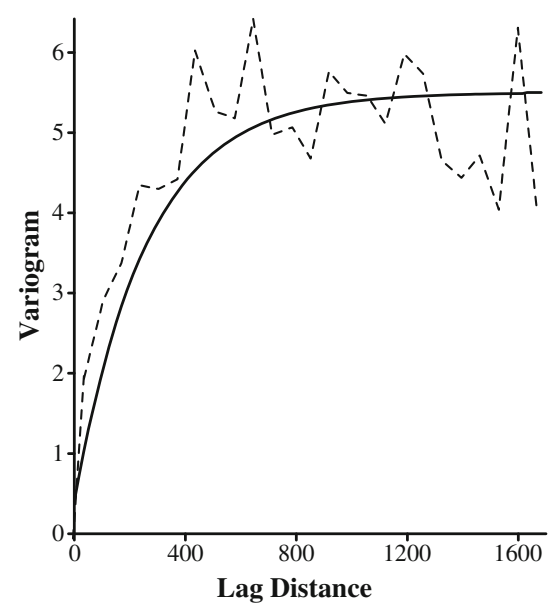

(f)

Figure 7. Variograms for $\left(\mathrm{N}_{1}\right)_{60 \mathrm{cs}}$ in depths of (a) $3 \mathrm{~m}$, (b) $6 \mathrm{~m}$, (c) $9 \mathrm{~m}$, (d) $13.5 \mathrm{~m}$, (e) $18 \mathrm{~m}$, (f) $25.5 \mathrm{~m}$. In all graphs, dashed and straight curves indicate the experimental and model variograms, respectively. 
In this study, Kriging was applied via Surfer software. Distinct variograms were prepared using data at different elevations. After fitting the appropriate theoretical mathematical models to experimental variograms, Kriging method was employed to prepare the iso- $\left(\mathrm{N}_{1}\right)_{60 \mathrm{cs}}$ maps.

\section{Results and discusion}

This study followed a step-wise procedure to map the SPT results in city center of Karşıyaka by geostatistics. After evaluation of data, models were fitted to experimental variograms and these

Table 1. Parameters belonging to the variogram models.

\begin{tabular}{lccccc}
\hline Parameter & Model & Nugget & Sill & Range & Focal direction \\
\hline $\mathrm{N}_{60 \mathrm{cs}}^{\prime} @ 3.00 \mathrm{~m}$ & Exponential & 0.60 & 22.30 & 350.1 & $45^{\circ}$ \\
$\mathrm{N}_{60 \mathrm{cs}}^{\prime} @ 6.00 \mathrm{~m}$ & Exponential & 0.40 & 30.71 & 261.3 & $45^{\circ}$ \\
$\mathrm{N}_{60 \mathrm{cs}}^{\prime} @ 9.00 \mathrm{~m}$ & Exponential & 0.25 & 26.22 & 259.5 & $45^{\circ}$ \\
$\mathrm{N}_{60 \mathrm{cs}}^{\prime} @ 13.5 \mathrm{~m}$ & Exponential & 0.35 & 14.20 & 372.5 & $45^{\circ}$ \\
$\mathrm{N}_{60 \mathrm{cs}}^{\prime} @ 18.00 \mathrm{~m}$ & Exponential & 0.21 & 6.82 & 397.6 & $45^{\circ}$ \\
$\mathrm{N}_{60 \mathrm{cs}}^{\prime} @ 25.5 \mathrm{~m}$ & Exponential & 0.13 & 5.44 & 262.4 & $45^{\circ}$ \\
\hline
\end{tabular}

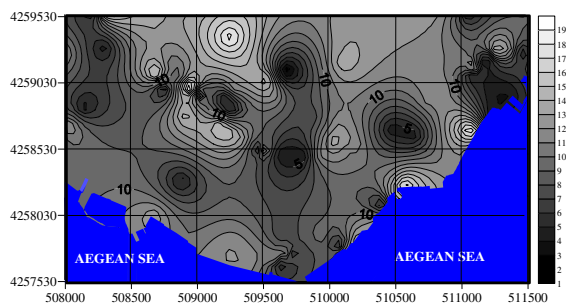

(a)

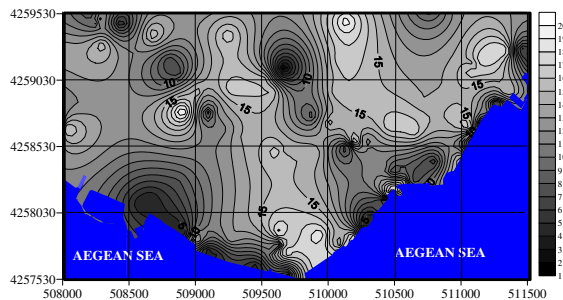

(c)

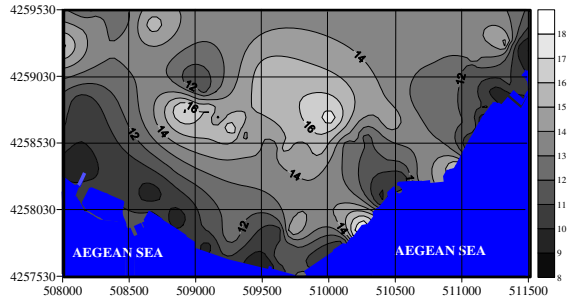

(e)

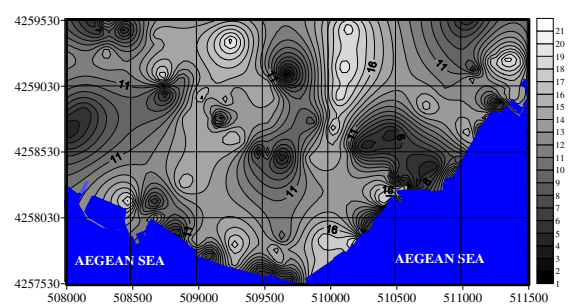

(b)

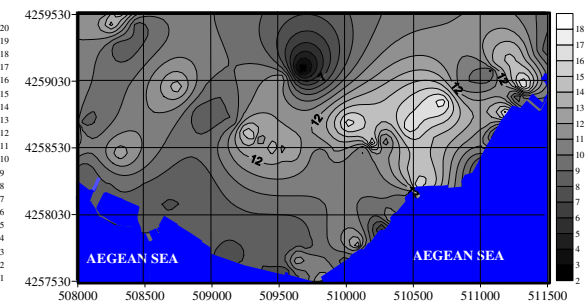

(d)

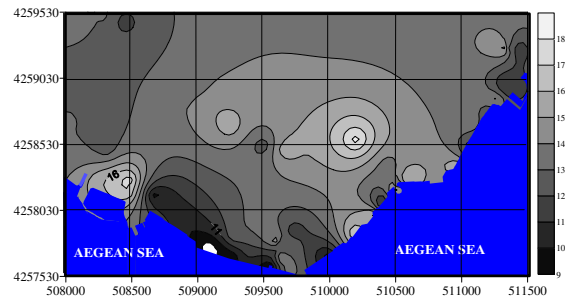

(f)

Figure 8. $\left(\mathrm{N}_{1}\right)_{60 \mathrm{cs}}$ variations in depths of (a) $3 \mathrm{~m}$, (b) $6 \mathrm{~m}$, (c) $9 \mathrm{~m}$, , (d) $13.5 \mathrm{~m}$, (e) $18 \mathrm{~m}$ and (f) $25.5 \mathrm{~m}$. 
variograms were used to prepare contour maps for $\left(\mathrm{N}_{1}\right)_{60 \mathrm{cs}}$ parameter, using ordinary Kriging method.

The variograms were given in figure 7. Geostatistical analyses were based on these variograms and great care was given to fit these models to the experimental variograms to a reasonable degree. The properties of these best-fit exponential models were given in table 1 .

Kriging technique was used to map the $\left(\mathrm{N}_{1}\right)_{60 \mathrm{cs}}$ values in various depths. In cells possessing limited subsurface geotechnical data, neighbouring borehole information and geological knowledge was used to create representative borehole data. In figure 8a, majority of the $\left(\mathrm{N}_{1}\right)_{60 \mathrm{cs}}$ values at $3 \mathrm{~m}$ depth showed variation between 5 and 19. Variation of these values at this depth was high and frequently observed values ranged between 8 and 12. It should be added that, a big amount of data was accumulated at value of 4 . For the $\left(\mathrm{N}_{1}\right)_{60 \mathrm{cs}}$ at $6 \mathrm{~m}$ depth (figure $8 \mathrm{~b}$ ), the observed values were frequently between 12 and 16 . Analysing figure $8 \mathrm{c}$, at $9 \mathrm{~m}$ depth, $\left(\mathrm{N}_{1}\right)_{60 \mathrm{cs}}$ values were accumulated at 15, whereas the frequency of 6 was remarkable. The values at the depth of 13.5, 18 and $25.5 \mathrm{~m}$, majority of the $\left(\mathrm{N}_{1}\right)_{60 \mathrm{cs}}$ values diminished between 7-10, 10-12 and 9-13; respectively. Although the variation of the $\left(\mathrm{N}_{1}\right)_{60 \mathrm{cs}}$ values ranged in a narrow interval, minimum values increased as we went deeper.

In order to examine modelling ability, absolute value of the residuals of $\left(\mathrm{N}_{1}\right)_{60 \text { cs }}$ parameter was contoured in figure 9. Computed absolute values of residuals were slightly higher for $3 \mathrm{~m}$

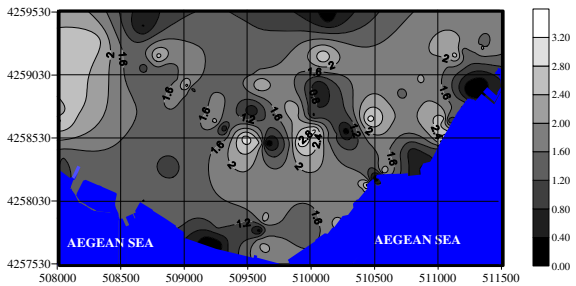

(a)

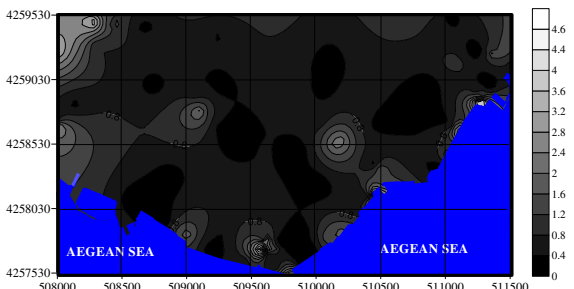

(c)

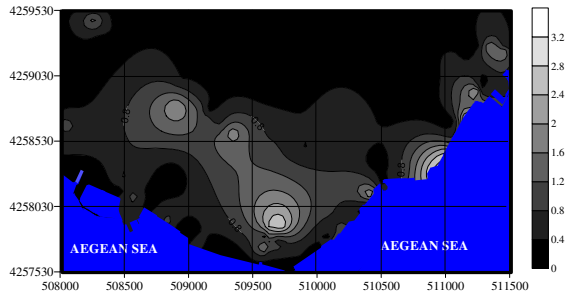

(e)

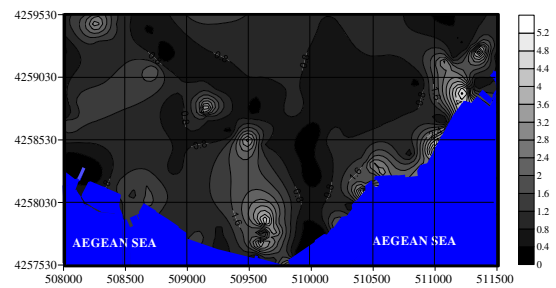

(b)

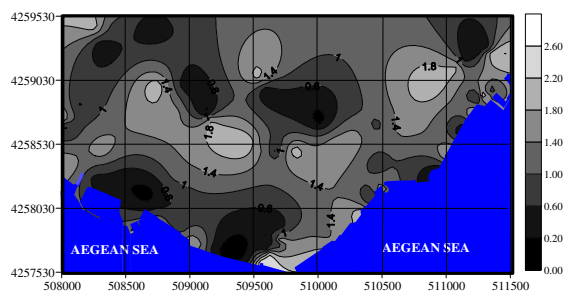

(d)

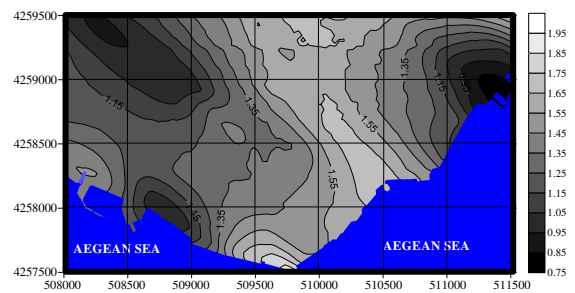

(f)

Figure 9. Map of the absolute value of $\left(\mathrm{N}_{1}\right)_{60 \mathrm{cs}}$ residuals for (a) $3 \mathrm{~m}$, (b) $6 \mathrm{~m}$, (c) $9 \mathrm{~m}$, (d) $13.5 \mathrm{~m}$, (e) $18 \mathrm{~m}$ and (f) $25.5 \mathrm{~m}$ depths. 
depth, and the high values of absolute value of residuals do not cover a significant area, in comparison with the total area under question. It was also observed that, after $9 \mathrm{~m}$, both the range and the maximum values of the absolute value of the residuals decreased. These graphs are given for evaluation of the error calculated in modelling corrected SPT values. However, even if the absolute value of the residuals were lower, it would be very assertive to advocate that these values can directly be used in design stage. These maps can only give an idea about the variation of the corrected SPT number.

Two bore holes logs were selected to present the variation of the real and estimated SPT results for a better performance assessment of the geostatistical approach. The estimated and real values belonging to bore holes B141 and B222 were given in figure 10. It was evident from the comparisons that the estimated and real values were very close to each other. Taking the errors in the field test application into consideration, it can be revealed that the errors were conservative.

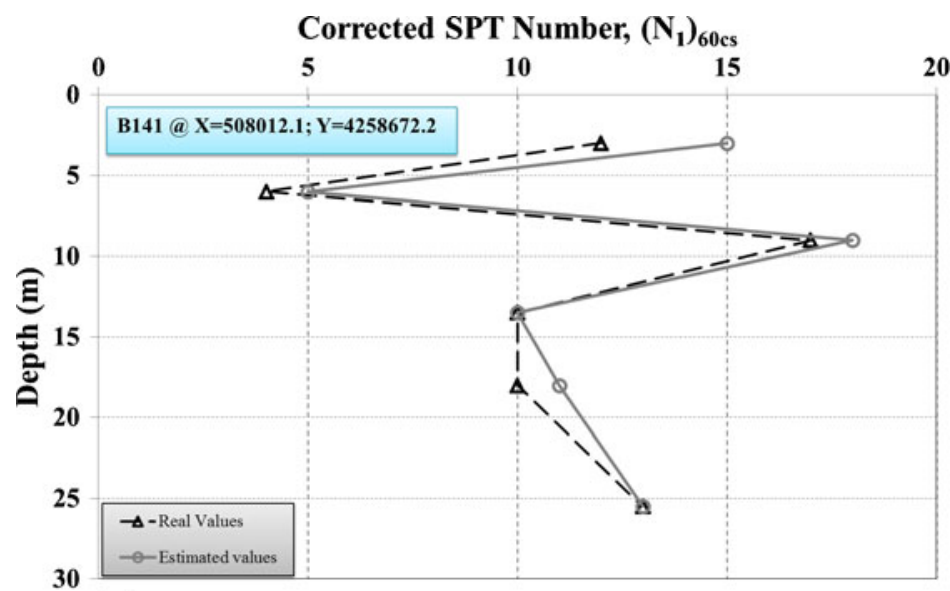

(a)

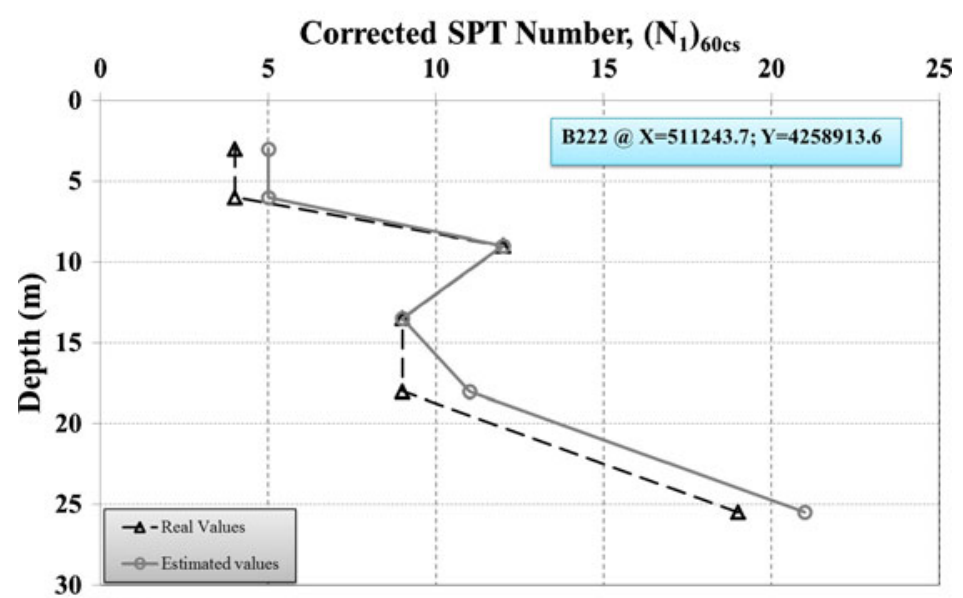

(b)

Figure 10. Estimated and real values of corrected SPT numbers in two borings. 
Table 2. Performance of the geostatistical models with reference to the real $\mathrm{N}_{60 \mathrm{cs}}^{\prime}$ values.

\begin{tabular}{lcc}
\hline Parameter & RMSE & MAE \\
\hline $\mathrm{N}_{60 \mathrm{cs}}^{\prime} @ 3.00 \mathrm{~m}$ & 1.719 & 1.494 \\
$\mathrm{~N}_{60 \mathrm{cs}}^{\prime} @ 6.00 \mathrm{~m}$ & 1.598 & 1.281 \\
$\mathrm{~N}_{60 \mathrm{cs}}^{\prime} @ 9.00 \mathrm{~m}$ & 1.689 & 1.411 \\
$\mathrm{~N}_{60 \mathrm{cs}}^{\prime} @ 13.5 \mathrm{~m}$ & 1.333 & 1.116 \\
$\mathrm{~N}_{60 \mathrm{cs}}^{\prime} @ 18.0 \mathrm{~m}$ & 1.037 & 0.853 \\
$\mathrm{~N}_{60 \mathrm{cs}}^{\prime} @ 25.5 \mathrm{~m}$ & 1.105 & 0.901 \\
\hline
\end{tabular}

Finally, in order to validate the model, two parameters were utilized. Root mean square error $(R M S E)$ and mean absolute error (MAE) parameters were calculated using the estimated and real values. MAE parameter is a simple means to the performance measure of a model

$$
M A E=\frac{1}{z}\left[\sum_{i=1}^{z}\left|p_{i}-y_{i}\right|\right],
$$

where $z, p_{i}$ and $y_{i}$ are the number of data, estimated value and real value, respectively. In addition to MAE, Root Mean Square Error (RMSE) is a common parameter used in evaluation of goodness-of-fit:

$$
R M S E=\sqrt{\frac{\sum_{i=1}^{z}\left(y_{i}-p_{i}\right)^{2}}{z} .}
$$

Similar to MAE, RMSE of a perfectly fit model converges to zero. These two parameters were calculated for modelling outcomes at every depth level and presented in table 2. Analysing the calculated values, it was observed that RMSE parameter ranged between 1.037 and 1.719, respectively. MAE values showed a decreasing trend as we went deeper. On the other hand, MAE values ranged between 0.853 and 1.494. Similar to MAE parameter, the RMSE values decreased as we went deeper. It should be emphasized that, as the depth increased, the performance of the models increased, which can be understood from the decreasing RMSE and MAE values. As a consequence, the RMSE and MAE values were considered to be reasonably low and the performances of the models were found acceptable overall.

\section{Conclusions}

This study aimed to benefit from kriging technique to determine the variation of corrected SPT numbers in Karşıyaka city center. Variograms were prepared at six depths for the data in hand. Subsequently, ordinary kriging method was used to calculate $\left(\mathrm{N}_{1}\right)_{60 \mathrm{cs}}$ values inside the area. Thereafter, contour maps were prepared for a better visualization of this variation. The models were validated using the RMSE and MAE parameters calculated at each depth, which were found to be reasonably low. Besides, the results obtained in two borings were compared with the estimated data, for a better visualization of the performance of the models. 
It was considered that the results obtained from 388 boreholes of this study can be useful for pre-evaluation of the subsurface strength in the area. The results of this study can be used to estimate several parameters (e.g., angle of internal friction, maximum shear modulus, shear wave velocity) related to the corrected SPT number inside the area.

It should be underlined that, the database in this study should be broadened to increase the modelling ability of the method. Further tests should be conducted in northwest and northeast of the area for more reliable estimations of this parameter.

\section{Acknowledgement}

This study is based on the data obtained from projects 105M336 and 106M013, supported by the Scientific and Technological Research Council of Turkey (TÜBİTAK).

\section{List of symbols}

\begin{tabular}{|c|c|}
\hline$a$ & Range in model \\
\hline$C$ & Variance between predetermined two points \\
\hline$C_{0}$ & Nugget in model \\
\hline$C_{B}$ & Borehole diameter correction \\
\hline$C_{E}$ & Hammer energy correction \\
\hline$C_{\text {fines }}$ & Fines content correction \\
\hline$C_{N}$ & Overburden pressure correction \\
\hline$C_{R}$ & Rod length correction \\
\hline$C_{S}$ & Sampler correction \\
\hline $\mathrm{CPT}$ & Cone penetration test \\
\hline CSR & Cyclic stress ratio \\
\hline$F C$ & Percentage of fines content \\
\hline GIS & Geographic information system \\
\hline$H$ & Lag distance between two points \\
\hline LPI & Liquefaction probability index \\
\hline MAE & Mean absolute error \\
\hline$\left(\mathrm{N}_{1}\right)_{60}$ & Corrected number of blow counts \\
\hline$\left(\mathrm{N}_{1}\right)_{60 \mathrm{cs}}$ & Number of blow counts corrected by fines content \\
\hline$N(h)$ & Number of data pairs separated within a predefined lag distance \\
\hline $\mathrm{p}$ & Estimated value \\
\hline $\mathrm{R}$ & Refusal in standard penetration test \\
\hline RMSE & Root mean square error \\
\hline SPT & Standard penetration test \\
\hline SPT-N & Experimentally obtained standard penetration value \\
\hline UTM & Universal transverse mercator \\
\hline$u$ & Location of variable $\mathrm{z}$ \\
\hline$y$ & Calculated value \\
\hline$z$ & Variable in kriging \\
\hline$\alpha$ & Lagrange coefficient used in the minimization of the error variance \\
\hline$\gamma(h)$ & Variogram \\
\hline
\end{tabular}




\section{References}

Al-Suba'i K A and Barat K A 2006 Ground conditions of Sana'a City, Yemen Republic. In: M G Culshaw, H J Reeves, I Jefferson and T W Spink (eds), $10^{\text {th }}$ Congress of the International Association for Engineering Geology and the Environment - Engineering geology for tomorrow's cities, Nottingham, Paper No.29, CD-ROM

Baecher G B 1984 On estimating auto-covariance of soil properties. In: Y K Wen (ed), Specialty Conference on Probabilistic Mechanics and Structural Reliability, ASCE, 1984, 110, 214-218

Baise L G, Higgins R B and Brankman C M 2006 Liquefaction hazard mapping-statistical and spatial characterization of susceptible units. J. Geotech. Geoenviron. Eng. 132(6): 705-715

Baker J W and Faber M H 2008 Liquefaction risk assessment using geostatistics to account for soil spatial variability. J. Geotech. Geoenviron. Eng. 134(1): 14-23

Basarir H, Kumral M, Karpuz C and Tutluoglu L 2010 Geostatistical modeling of spatial variability of SPT data for a borax stockpile site. Eng. Geol. 114(3-4): 154-163

Bowles J E 1997 Foundation analysis and design. Singapore: McGraw-Hill Book Company, 1024 p

Budhu M 2007 Soil mechanics and foundations. U.S.A.: Wiley $780 \mathrm{p}$

Carvalho J J C M and Cavalheiro A A T 2005 Geostatistical and fourier analysis applied to cross-hole tomography seismic data. Quant. Geol. Geostat. 14(4): 843-852

Çetin K O, Seed R B, Der Kiureghian A, Tokimatsu K, Harder L F Jr, Kayen R E and Moss R E S 2004 Standard penetration test-based probabilistic and deterministic assessment of seismic soil liquefaction potential. J. Geotech. Geoenviron. Eng. 130(12): 1314-1340

Çiftçi N B and Bozkurt E 2009 Evolution of the Miocene sedimentary fill of the Gediz Graben, SW Turkey. Sediment. Geol. 216(3-4): 49-79

Dawson K M and Baise L G 2005 Three-dimensional liquefaction potential analysis using geostatistical interpolation. Soil Dyn. Earthq. Eng. 25(5): 369-381

Duval R, L'evy R and Matheron G 1955 Travaux de D. G. Krige sur l'evaluation des gisements dans les mines d'or sud-africaines. Ann. Min. 12: 3-49

Emre Ö, Özalp S, Doğan A, Özaksoy V, Yıldırım C and Göktaş F 2005 Active faults in the vicinity of İzmir and their earthquake potential. Report No:10754, Turkish General Directorate of Mineral Research and Exploration

Huijbregts C J 1975 Regionalized variables and quantitative analysis of spatial data. Display and analysis of spatial data. In: J C Davis, M J Mc Cullagh (eds), New York: John Wiley, 378 p

Jaksa M B 1995 The influence of spatial variability on the geotechnical design properties of a stiff, overconsolidated clay. Ph.D. thesis, Faculty of Engineering, The university of Adelaide, Australia, $451 \mathrm{p}$

Journel A 1989 Fundamentals of geostatistics in five lessons. Short course in geology. Washington, D.C.: American Geophysical Union, $134 \mathrm{p}$

Koca Y and Kincal C 2004 Abandoned stone quarries in and around the Izmir city centre and their geoenvironmental impacts-Turkey. Eng. Geol. 75(1): 49-67

Krige D G 1951 A statistical approach to some basic mine valuation problems on the Witwatersrand. J. Chem. Metall. Min. Soc. S. Afr. 52(6): 119-139

Lenz J A and Baise L G 2007 Spatial variability of liquefaction potential in a region mapping using CPT and SPT data. Soil Dyn. Earthq. Eng. 27(7): 690-702

Mansor S S B 2003 Analysis of site classification for Kuala Lumpur's ground assessment. M.Sc. Thesis, Civil Engineering Faculty, Universiti Sains Malaysia, 174 p

Matheron G 1970 The theory of regionalized variables and its applications. No.5 in Les Cahiers du Centre de Morphologie Mathématique. Ecole de Mines de Paris, Fontainebleau, 207 p

Mendes R M and Lorandi R 2003 Study of SPT behavior of penetration resistance under influence of the groundwater level fluctuation, using geostatistical methodology. RMZ-Mater. Geoenviron. 50(1): 225-228

Mendes R M and Lorandi R 2008 Analysis of spatial variability of SPT penetration resistance in collapsible soils considering water table depth. Eng. Geol. 101(3-4): 218-225 
Olea R A (ed) 1991 Geostatistical glossary and multilingual dictionary. USA: Oxford University Press, $192 \mathrm{p}$

Önalp A and Sert S 2010 Geotechnical information III: foundations. İstanbul: Birsen Publisher, 426 p (in Turkish)

Parsons R L and Frost J D 2002 Evaluating site investigation using GIS and geostatistics. J. Geotech. Geoenviron. Eng. 128(6): 451-461

Rota 2007 Estimating uncertainty in 3D Modeling using statistics. Ph.D. Thesis, Universita degli Studi di Pavia, $116 \mathrm{p}$

Samui P and Sitharam T G 2010 Site characterization model using artificial neural network and kriging: Int. J. Geomech. 10(5): 171-180

Sitharam T G and Samui P 2007 Geostatistical modelling of spatial and depth variability of SPT data for Bangalore. Geomech. GeoEng. 2(4): 307-316

Sivrikaya O and Togrol E 2006 Determination of undrained strength of fine-grained soils by means of SPT and its application in Turkey. Eng. Geol. 86(1): 52-69

Whitman R V 2000 Organizing and evaluating uncertainty in geotechnical engineering. J. Geotech. Geoenviron. Eng. 126(7): 583-593 